Session 2793

\title{
Disseminating Biomedical Engineering Concepts to 8th -12th Grade Teachers
}

\author{
Steve Schreiner and John Burns \\ Western New England College, Springfield Massachusetts/ \\ Agawam Public Schools, Agawam Massachusetts
}

\begin{abstract}
In order to increase the exposure of K-12 students to biomedical engineering concepts, a statewide summer workshop funded by the Massachusetts State Department of Education was developed by the Biomedical Engineering Program at Western New England College in collaboration with Agawam Public Schools, a local school system. The objectives of this workshop included increasing the awareness of the biomedical engineering field, giving teachers educational modules to bring back to their own classrooms, and to help the teachers fulfill the requirements of the state's science and technology curriculum that includes topics in biomedical engineering.

The workshop spanned two weeks and included many topics, hands-on interactions, and two field trips. Topics included: the engineering design process, gait analysis, genetics, biomedical devices and control systems, biomedical modeling, technical presentation techniques, and the man-machine interface. Workshop instructors included professors from the College, as well as two teachers from Agawam Public Schools. There was a strong synergy between engineering experts and pre-college educators - the overarching philosophy of workshop was that both groups need to come together as equal partners to successfully bring biomedical engineering concepts into the pre-college students' curriculum. Time was spent each day on activity called "putting it into practice" in which the pre-college teachers presented ideas of how to fit the topic presented the previous day into their own teaching plan. Essentially, this became an outline for a full lesson plan. At the end of the workshop the teachers developed at least one full lesson to bring back to their classroom. The teachers reconvened in the Fall of 2000 to discuss how well the new lessons worked. The workshop was a success with many teachers incorporating several concepts into their lesson plans.
\end{abstract}

\section{Introduction}

Western New England College and Agawam Public Schools cosponsored a two-week workshop on biomedical engineering (BME) for middle and high school teachers during the summer of 2000. This workshop was funded by a grant from the Massachusetts Department of Education as a "content institute" to provide K-12 teachers with professional development targeted at the statewide curriculum. Massachusetts is the first state in the country to require engineering topics as learning objectives for all K-12 students.

With this new emphasis on pre-college engineering, there is a need for engineering and K-12 educators to collaborate on ways to meet educational objectives. The benefits of such collaborations extend well beyond the professional development of the educators. Exposing pre- 
college students to the engineering principles in the context of the latest technological developments will increase motivation to study pre-college science and math and will increase the number of students pursuing degrees in engineering and science. Additionally, the engineering professors become familiar with the pre-college curriculum allowing for engineering curricular enhancements, particularly in the freshman, transition year.

Engineering schools' efforts to expose pre-college teachers to engineering are certainly not new and have taken on several forms including exposing both pre-college teachers and students to engineering concurrently [1]. Working with teachers to integrate engineering concepts into their curriculum has the potential to expose many future generations of students to engineering concepts, especially those students that have not already considered engineering as a career. Other programs have successfully interacted with teachers by focusing on specific, traditional engineering concepts such as application of mechanics or material science to engineering designs such as bridges $[2,3,4]$.

Biomedical engineering concepts are ideal to incorporate into pre-college students' curricula because of the multidisciplinary nature of the field (e.g. one can easily discuss the mechanical, electrical, or chemical properties of the cardiac system). Moreover, BME has the potential to attract students who may not be considering a traditional engineering career by showing how engineering principles can directly improve the healthcare of individuals. Many students have personal experiences that make solving medical problems of interest to them.

Biomedical engineering as an undergraduate degree option is relatively new and not as widely known as the traditional engineering disciplines among pre-college students. Providing educational material to K-12 educators is an effective and lasting way of exposing students to the field. By incorporating BME examples directly into the pre-college curriculum, students are motivated at an early age to begin to integrate biology, mathematics and engineering; a process that has traditionally only occurred in higher education (mostly at the graduate level).

Although this workshop targeted middle and secondary educators, the concepts were presented in a manner that allows modification for any grade level or course. The educational modules and concepts were not rigidly designed prior to the workshop, rather the participants and presenters worked together to tailor the modules for a particular pre-college curriculum.

\section{Content}

The field of Biomedical Engineering is very broad. Representing the entire field in a meaningful way in a two-week institute is difficult. It was decided that a variety of topics should be covered at an appropriate depth such that each teacher could bring that topic back to their classroom. Topics included the engineering design process, BME modeling, gait analysis, genetics, biomedical devices, control systems, ergonomics and anthropometrics, and applying BME principles to the Massachusetts curriculum frameworks. The laboratory experiences were constructed as stand alone modules that could easily be adapted to a particular grade level and course.

The institute began with an introduction to engineering, biomedical engineering, and the design process. As with every topic presented at the workshop, the participants actively participated in learning the material. The participants were guided through solving two problems. The first 
time through the design process, each step was first discussed in detail and together as a class the steps were followed to solve the problem. The second time through the design process the class was divided into teams of three members each and each team went through each step. Each team then presented their ideas to the rest of the class.

One day of the institute was spent studying modeling of physiological systems. The day centered on the purpose of modeling and applications of modeling to the cardiac and vascular systems. In an associated laboratory exercise, the participants measured the compliance of flexible tubing that represented vascular segments with varying degrees of arteriosclerosis. Pressure and volume data was gathered and plotted using excel.

The participants also focused one day on the study of human motion and gait analysis. During a laboratory exercise the participants measured their own gait parameters, something that is easily reproduced in their own classrooms. A portion of the day was devoted to visiting a local hospital and participating in a clinical gait evaluation using state-of-the-art motion analysis system.

Two days were spent discussing genetics. The first day focused on basic principles and terminology as well as a field trip to a local agricultural facility to see application of genetics and microbiology to agriculture. The entire second day was spent in the laboratory performing polymerase chain reaction (PCR) and electrophoresis.

The participants learned about many of the advanced biomedical devices used in the clinic and newly developing devices that are still in the research laboratories. The intent of this session was to give the teachers many high-tech biomedical applications that they could disseminate to their students as motivation to study mathematics and science. Moreover, the participants selected a device of interest to them and presented a technical poster about this device to the rest of the class at the end of the workshop.

Motivated by the advanced devices (many of them utilizing control systems), the participants spent a day learning about basic control systems and sensors. RoboLab ${ }^{\mathrm{TM}}$ kits by LEGODACTA served as the platforms building devices. These kits include light sensors, angle sensors, limit switches, motors, and a programmable controller that were used to build simple vehicles that used feedback to control the path of the vehicle.

Finally, the participants learned about designing for the man-machine interface and other ergonomic principles. The participants made measurements of their own anatomy and compared their statistics to the general population. Emphasis was placed on how this information is used to design devices that must interact with the human body. Again, the content of the discussion and associated laboratories were easily transferred to middle or secondary students.

\section{High Education and K-12 Partners}

The institute was open to all Massachusetts teachers; several grade levels and disciplines were represented including chemistry, biology, technology, and health. School systems from literally across the state were represented. 
The pre-college educators were motivated to work with the higher education professionals to discuss challenges associated with teaching the engineering perspective to their students. A key the success of this workshop was the notion that the pre-college and engineering educators each brought their expertise to the table with an open mind. The engineering professors are experts in engineering but know little about teaching middle school science to the entire population! The premise throughout the workshop was that the engineering professors would present engineering concepts and then the participants would work as a group on ways of incorporating the concepts into particular grade levels and courses. Working together as partners, many pragmatic issues were discussed and many excellent ideas were openly shared. The pre-college teachers were able to identify many places in their existing curriculum where changes (sometimes minor) could be made to bring an engineering perspective to task to be performed. This allowed the teachers to consider including many ideas into their classrooms without eliminated large portions of existing content.

All of the equipment used during the workshop was made available to the teachers throughout the academic year to help facilitate their curricular changes.

\section{Putting it into Practice}

Every evening the participants were given the assignment of outlining a lesson plan that utilized the information covered that day. Specific learning objectives from the Massachusetts curriculum framework were identified for each lesson. The next morning the participants presented their ideas to each other in an open forum where the initial ideas began to mature and new ideas were created.

As a requirement of receiving professional credit and graduate credit for participating in the institute, the participants were required implement at least one new idea into this year's lesson plan. Moreover, they were required to gather again as a group to discuss how well these new lessons worked.

A follow-up session held in December 2000 yielded further evidence of the success of the institute. All the teachers incorporated several aspects of the institute into their classes. For example, one interesting idea came from one of the participants who is a physical therapist working with special education students in the public schools. She took what she learned about the design process and partnered with a local shop teacher to have the shop students design walking aids for some of her special needs students. Not only did these students learn about a methodical way to solve medical design problems, they interacted with a segment of the student body that benefited from their ideas. This is a great way to teach students to be empathetic of others, something that is otherwise a difficult concept for students to grasp from a traditional curriculum.

Other concepts included using the design process to solve both medically related problems and other problems (e.g. traffic flow problems), ergonomic and gait measurements, vascular (analog) compliance measurements, and technical poster presentations. Learning a systematic approach to solving problems seemed to be of great interest to most of the participants and is evidenced by the fact that the process discussed in the workshop has been used by students to solve problems outside the topics discussed in the institute. 


\section{Conclusions}

The biomedical engineering workshop for middle and high school teachers was a success. The teachers successfully incorporated educational modules and concepts from the workshop into their classrooms. The challenge of representing the broad field of biomedical engineering was met by focusing on specific educational modules from various areas within the field. The handson modular approach allowed the participants to gain a depth of knowledge about a specific BME application without spending a large amount of time on background material. This effort was furthered by choosing topics that are at least familiar to the participants or conceptually easy to grasp (e.g. vascular disease, gait analysis, anthropometric measures, etc. ).

Collaboration between engineering professors and K-12 educators is working to improve K-12 curricula by including engineering concepts. An equal partnership was formed between K-12 and college educators so that a true synergy occurred. This partnership allowed for a dynamic environment where educational modules being presented could be tailored to specific pre-college classroom environments.

\section{Acknowledgements}

The authors wish to thank the following people whose contributions were important to the success of this project: Dr. Ronald Musiak, Dr. Gail Fletcher, Dr. Karoush Rahnamai, Dr. Abdul Kamal, Ms. Marilyn Sullivan, and Mr. Michael Tedesco of Western New England College; Mr. Richard Joseph, Ms. Cele Daigneau, and Ms. Rene O. Jury of Agawam Public Schools; and Mr. George Gorton, Mr. David A. Hebert, and Mr. Owen F. Kelly of Shriners Hospital for Children, Springfield, MA.

\section{References}

[1] Stevens, Karl K. and Sharon M. Schlossberg, "Technology connection - a program for precollege orientation and recruiting." Proceedings of the ASEE Annual Conference, Seattle, WA, June 28- July 1, 1998.

[2] Zachary, Loren W., Janet M. Sharp, and Barbara M. Adams, "Engineering connections: Teaching engineering mechanics to K-12 teachers."Proceedings of the ASEE Annual Conference, St. Louis, MO. June 18- 21, 2000.

[3] Sharp, Janet M., Tracy L. Chandler, and John A. Petersen, "Teaching teachers to apply engineering: a tale of two high school classrooms." Proceedings of the ASEE Annual Conference, St. Louis, MO. June 18- 21, 2000.

[4] Muller, Carol B. and William S. Carlsen. "Fostering educational innovation at the level of individual professionals in K-12: a case study." Proceedings of the $27^{\text {th }}$ Annual Frontiers in Education Conference, Pittsburgh, PA, Part 1 (of 3), pp 521-5, Nov 5-8 1997. 
STEVE SCHREINER

Steve Schreiner is an Assistant Professor and Coordinator of Biomedical Engineering at Western New England College in Springfield, Massachusetts. Dr. Schreiner received his Ph.D. and M.S.B.E at Vanderbilt University, and his B.S.E.E. at Western New England College. He held a two-year National Institutes of Health (NIH) postdoctoral fellowship at Johns Hopkins University. He has held engineering positions in industry and is a Registered Professional Engineer in Tennessee. His interests include engineering education, advanced surgical navigation devices, medical instrumentation, and medical imaging.

\section{JOHN BURNS}

John Burns is Academic Coordinator for Technology Education for Agawam Public Schools in Agawam Massachusetts. Mr. Burns has earned his Masters Degree equivalency from the Agawam School Committee and the BA in Mathematics with a minor in secondary education from Westfield State College in Westfield, Massachusetts. He has taught mathematics and technology at the middle and high school levels. Mr. Burns has been honored with several teaching awards and is an expert in developing pre-college technology curricula and has organized and participated in many state sponsored workshops. 